GRASAS Y ACEITES 68 (2)

April-June 2017, e195

ISSN-L: 0017-3495

doi: http://dx.doi.org/10.3989/gya.1275162

\title{
Rapid NIR determination of alkyl esters in virgin olive oil
}

\author{
J.A. Cayuela ${ }^{\square}$ \\ Instituto de la Grasa, CSIC. Campus Universitario Pablo de Olavide, Edificio 46, Ctra. de Utrera km 1, 41013, Sevilla. \\ ${ }^{\square}$ Correspondence: jacayuela@ig.csic.es
}

Submitted: 20 December 2016; Accepted: 06 March 2017

SUMMARY: The regulation of The European Union for olive oil and olive pomace established the limit of $35 \mathrm{mg} \cdot \mathrm{kg}^{-1}$ for fatty acids ethyl ester contents in extra virgin olive oils, from grinding seasons after 2016. In this work, predictive models have been established for measuring fatty acid ethyl and methyl esters and to measure the total fatty acid alkyl esters based on near infrared spectroscopy (NIRS), and used successfully for this purpose. The correlation coefficients from the external validation exercises carried out with these predictive models ranged from 0.84 to 0.91 . Different classification tests using the same models for the thresholds $35 \mathrm{mg} \cdot \mathrm{kg}^{-1}$ for fatty acid ethyl esters and $75 \mathrm{mg} \cdot \mathrm{kg}^{-1}$ for fatty acid alkyl esters provided success percentages from $75.0 \%$ to $95.2 \%$.

KEYWORDS: Alkyl esters; Ethyl esters; NIRS; Olive oil; Quality; Sensory defects

RESUMEN: Determinación rápida de ésteres alquílicos en aceite de oliva virgen para detección temprana de defectos sensoriales. La reglamentación de la Unión Europea para el aceite de oliva y el orujo de oliva ha establecido el límite de $35 \mathrm{mg} \cdot \mathrm{kg}^{-1}$ al contenido de ésteres etílicos de ácidos grasos en los aceites de oliva virgen extra, para campañas de molienda posteriores a 2016. En este trabajo se han establecido modelos predictivos para medir los ésteres etílicos y metílicos de ácidos grasos y para la medida de los ésteres alquílicos de ácidos grasos totales basados en la espectroscopía de infrarrojo cercano (NIRS) y utilizados con éxito para este propósito. Los coeficientes de correlación de los ejercicios de validación externa realizados con estos modelos predictivos oscilaron entre 0,84 y 0,91 . Diferentes pruebas de clasificación utilizando los mismos modelos con respecto a los umbrales de $35 \mathrm{mg} \cdot \mathrm{kg}^{-1}$ para ésteres etílicos y $75 \mathrm{mg} \cdot \mathrm{kg}^{-1}$ para ésteres alquílicos, proporcionaron porcentajes de éxito del $75,0 \%$ al $95,2 \%$.

PALABRAS CLAVE: Aceite de oliva; Calidad; Defectos sensoriales; Ésteres alquílicos; Éteres etílicos; NIRS

ORCID ID: Cayuela JA http://orcid.org/0000-0001-9026-631X

Citation/Cómo citar este artículo: Cayuela JA. 2017. Rapid NIR determination of alkyl esters in virgin olive oil. Grasas Aceites 68 (2), e195. http://dx.doi.org/10.3989/gya.1275162

Copyright: (C) 2017 CSIC. This is an open-access article distributed under the terms of the Creative Commons Attribution (CC-by) Spain 3.0 License. 


\section{INTRODUCTION}

Virgin olive oil is the natural juice of the olive, which is usually a product of good or high quality. However, some processing steps are susceptible to product deterioration. After separating the solid and the aqueous phase from the olive oil, a series of sieves are needed. Each of these elements, specially the decanter, is difficult to keep clean (Alba, 2013) and the presence of foam is frequent. Under these conditions, alcoholic fermentation may produce ethanol or methanol in certain quantities, which constitutes substrates for esterification, thus lending sensory defects to olive oil (Gómez-Coca et al., 2012).

Fatty acid alkyl esters (FAAEs) are formed by the esterification of short chain alcohols, mainly ethanol and methanol, with free fatty acids, yielding ethyl and methyl esters, respectively (Gómez-Coca et al., 2012). In fact, the most frequent olive oil defects are due to fermentation processes. This is the case of the fusty (atrojado) defect, characteristic of olives stored in piles, where anaerobic fermentation occurs. However, aerobic fermentation may happen in the foam of the decanters, as mentioned above. When FAAEs reach a certain concentration, they make fermentative alteration evident (Pérez-Camino et al., 2002). For this reason, a relationship between the FAAE concentration of olive oils and their sensory classification has been proposed, and a link between the presence of large quantities of FAAEs in olive oil and its fermentative sensory defects has been proven (Gómez-Coca et al., 2012). Therefore, techniques for rapid determination of FAAEs in virgin olive oil for the early detection of sensory defects would be very useful.

The EU regulation for olive oil and olive pomace (European Commission Regulation, 1991) requires the presence of the fruity attribute and the complete absence of sensory defects, together with other physicochemical characteristics such a free acidity below $0.8 \%$ in order for an oil to be classifies as EVOO. In contrast, VOO admits the presence of sensory defects below 3.5 on a scale of 10 , and maximum acidity of $2 \%$. The most recent amendment of the EU regulation (European Commission Regulation, 2016) established the limit of $35 \mathrm{mg} . \mathrm{kg}^{-1}$ for fatty acid ethyl esters (FAEEs).

The relationship between ethanol and the olive oil sensory defects muddy, mold, fusty and vinegary must be emphasized. The presence of ethanol reveals the remarkable influence of alcoholic fermentation on the sensory defects from a microbial origin, which is most common to virgin olive oil (Cayuela et al., 2015). Methanol is also present in the last three defects above, according to data from Procida et al. (2005). Methanol toxicity is more than 300 times higher than that of ethanol according to the international chemical safety data sheets of both alcohols. Therefore, although fatty acid methyl esters (FAMEs) have not been included in the regulation mentioned above, the methanol and FAME contents are important factors in olive oil quality, and it is essential to measure them.

Among the various non-destructive and rapid techniques that can offer solutions for measuring FAAEs in virgin olive oil, near infrared spectroscopy (NIRS) technology, based on chemometrics, has provided major achievements. It offers several advantages, such as being a non-destructive and rapid, potentially multiparameter method. In addition, it is environmentally friendly, since no solvents or reagents are used. The suitability of measuring the main parameters of olive oil quality, such as free acidity, peroxides, K270 and K232 by NIRS has been reported several times (Conte et al., 2003; Mailer, 2004; Armenta et al., 2007; Bendini et al., 2007; Costa et al., 2008). In fact, the number of laboratories using NIRS techniques for routine analysis of these parameters is continuously increasing. Vis/ NIRS has been reported to be a suitable method for determining the Oil Stability Index (OSI) (Cayuela et al., 2013), which measures olive oil oxidation.

Direct GC-MS with electron ionization (Boggia et al., 2014) has been reported as an advantageous method for FAAE analysis in addition to the UE and IOC official method (European Commission Regulation, 1991), which is the most frequent. Mid infrared spectroscopy (Valli et al., 2013) and time domain reflectometry (Berardinelli et al., 2013), both based on chemometric approaches, are the most unique, rapid techniques reported up to date for FAAE analysis in olive oils without requiring sample preparation.

Considering the above background, it might be useful to have rapid, alternative methods for detecting and quantifying FAAEs and FAEEs in olive oils, as this would allow early detection of fermentation defects in the product. In the present work a NIRS rapid, non-destructive, and environmental friendly technique for the screening of FAAEs, FAEEs, and FAMEs in olive oil is reported.

\section{MATERIALS AND METHODS}

\subsection{Olive oils}

Olive oils from two different sample groups were used. A collection of olive oils preserved at the Instituto de la Grasa (IG-CSIC) provided 483 olive oil samples (set I), collected from different origins, composed of extra virgin, virgin, and lampante olive oil. Another sample group composed of 124 samples of the same olive oil types (set II) was provided by AINIA Technology Center (Paterna, Spain) within a research service.

\subsection{Instrumentation}

Spectral acquisition was performed for every sample with two different spectrometers. The purpose of this was to assess the performance of different optical and constructive features, as well as 
to test the utility of using visible wavelengths which perhaps may be related directly or indirectly to any compounds implied in fatty acid alkyl ester formation, which cannot be ruled out a priori.

Labspec (Analytical Spectral Devices Inc., Boulder) is a Visible/NIR spectrometer, with three detectors. The visible range $(350-1000 \mathrm{~nm})$ is processed by a diode array detector with a sensitivity of 512 pixels. Wavelengths in the visible spectrum may provide information directly or indirectly related to the quality parameters analyzed. The wavelength range of $1000-1800 \mathrm{~nm}$ is covered by a $\mathrm{InGaAs}$ detector cooled at $-25^{\circ} \mathrm{C}$. The same device combined with a high order blocking filter operates for the 1800$2500 \mathrm{~nm}$ interval. The scanning speed is $100 \mathrm{~ms}$. A spectrophotometric cuvette accessory (Ocean Optics, Dunedin) joined by fiber optic connectors, was used. The olive oil spectra were registered with Indico Pro software (Analytical Spectral Devices Inc., Boulder).

Luminar 5030 (Brimrose Corp., Maryland) is an AOTF (acousto-optic tunable filter) NIR spectrophotometer, equipped with a reflectance post dispersive and InGaAs (1100-2300 $\mathrm{nm})$ detector. The reference is automatically taken by the instrument. The scanning speed in Luminar 5030 is $60 \mathrm{~ms}$. The spectrometer is equipped with a transflectance probe for liquid measurements in stainless steel. This probe has interchangeable threaded path lengths, and 0.5 $\mathrm{cm}$ is used for olive oil. The signals were registered with software Acquire (Brimrose Corp., Maryland).

\subsection{Spectral acquisition}

For both spectrometers the whole spectrum was registered, with spectral variables at $1 \mathrm{~nm}$ interval each. Each sample is represented by an average spectrum, resulting from a total 100 spectra corresponding to two replicates of 50 spectra each.

The temperature of a body influences the NIR radiation it reflects and absorbs, hence it is an important factor in NIRS. In order to set the thermal conditions for using the calibrations, the samples were taken from $4{ }^{\circ} \mathrm{C}$ storage and placed in the lab $18 \mathrm{~h}$ before processing. Prior to the recording of spectra, the sample vials were placed in a thermostatic bath at $33{ }^{\circ} \mathrm{C}$ to check the stability of temperature. The recording of spectra was made nondestructively from each virgin olive oil sample without any other treatment. The acquisition with Labspec was carried out by transmittance, using the spectrophotometric cuvette accessory. The same operation with Luminar 5030 was carried out using its transflectance probe.

\subsection{Reference analysis}

The reference analyses for the determination of FAEEs, FAMEs and FAAEs were conducted according to the official method established by The EU (European Commission Regulation, 1991). Fatty acids methyl ester (FAMEs) values from the sample set II were provided by The AINIA Technology Center. The analysis method for FAAEs and FAMEs was the same as described for FAEEs. The reference analysis was done in duplicate.

\subsection{Calibration procedure and chemometrics}

Transmittance spectral data were transformed to absorbance. Mean and maximum normalization and second Savitzsky Golay derivatives were tested. The calibration sets for all models were formed once the external validation sets from the total of the olive oil samples available were excluded, as indicated below. Therefore, the external validation sets reserved were not included in the multivariate models. Partial Least Square (PLS) models for FAAEs, FAEEs and FAMEs were developed starting from the whole spectrum using The Unscrambler 9.7 (CAMO Software AS, Norway), with the full cross internal validation (FCV) procedure. The models' principal components (PCs) were fixed after probes, using ten PCs initially. The procedure for selecting the spectral variable participating in the models consisted of several consecutive cycles. These consisted of eliminating those variables whose spectral correlation coefficients with the analyzed parameter were closer to zero. Variable selection ended in the last cycle which improved the statistical model $\mathrm{R}^{2}$ and $\mathrm{R}_{\mathrm{CV}}^{2}$. This selection was made on the regression coefficient graph of The Unscrambler 9.7.

Model fitness was assessed independently of the model validation procedure described below according to its proximity between $\mathrm{R}^{2}$ and $\mathrm{R}_{\mathrm{CV}}^{2}$ and standard error of calibration (SEC).

\subsection{Model performance assessment}

The calibration models were assessed by external validation exercises which make predictions on the validation set previously reserved. The validation sets for FAAEs $\left(\mathrm{V}_{\mathrm{a}}\right)$, FAEEs $\left(\mathrm{V}_{\mathrm{e}}\right)$, and FAMEs $\left(\mathrm{V}_{\mathrm{m}}\right)$, were built by selecting one of every five of the total olive oil samples available counting from the first, which were not used for calibration and reserved. Model performance was assessed mainly according to the coefficient $r$ of the simple linear regression between the analyzed and the predicted values in the external validation exercises. This statistic is proposed as the most suitable for the purpose of a rapid detection of a significant presence of total FAAEs and FAEEs in olive oils, as discussed later. Their SEC and SEP were also considered.

After the previous tests, the model FAAEs, FAEEs and FAMEs were used in the same external validation sets for detecting those samples with values higher than FAAEs 75 mg.kg-1 or FAEEs $35 \mathrm{mg} . \mathrm{kg}-1$ according to the thresholds previously mentioned. The outcomes are expressed as percentage of prediction success. The model prediction is 
considered a success if is higher than these thresholds when the reference value is above this limit, as well as when the prediction values lower than this threshold also matches a reference value lower than it.

\section{RESULTS}

\subsection{Olive oil spectrum}

Near-infrared spectra are composed of various bands which overlap as a result of the first and second overtones and a combination of the fundamental vibrations, mainly carbon-hydrogen. The assignment of the major near-infrared absorption bands of vegetable oils' spectra has been described by Sato et al. (1991). Monounsaturated fatty acids match with the first overtones at $1,724 \mathrm{~nm}$ and $1,766 \mathrm{~nm}$, and with their combination at 2,358 $\mathrm{nm}$. Polyunsuturated fatty acids relate to the first and second overtones and their combination at eight different wavelengths. Triolein is assigned to a first overtone at $1,725 \mathrm{~nm}$, and with a combination at $2,143 \mathrm{~nm}$. Wavelengths in the region of $1,800 \mathrm{~nm}$ seem to be characteristic of saturated fatty acids (García-González et al. 2013). The assignment of the major visible absorption bands of olive oil has been described by Moyano et al. (2008).

Olive oil spectra acquired with Labspec from the samples analyzed in this work, shown in Figure 1, agree with the previously indicated reports. A broad absorbance band exists around $1220 \mathrm{~nm}$, due to second overtones of $\mathrm{C}-\mathrm{H}$ and $\mathrm{CH}=\mathrm{CH}-$ stretching vibrations. Absorption intensity near $1,720 \mathrm{~nm}$ is characteristic of the first overtone of the $\mathrm{C}-\mathrm{H}$ vibration of various chemical groups $(-\mathrm{CH} 3,-\mathrm{CH} 2$, $=\mathrm{CH}-$ ) and varies according to analyzed TAGs. A high intensity absorbance peak occurs at about 2300 $\mathrm{nm}$ which is caused by a combination of fundamental vibrations from the C-H groups (Sato et al., 1991: Hourant et al., 2000).

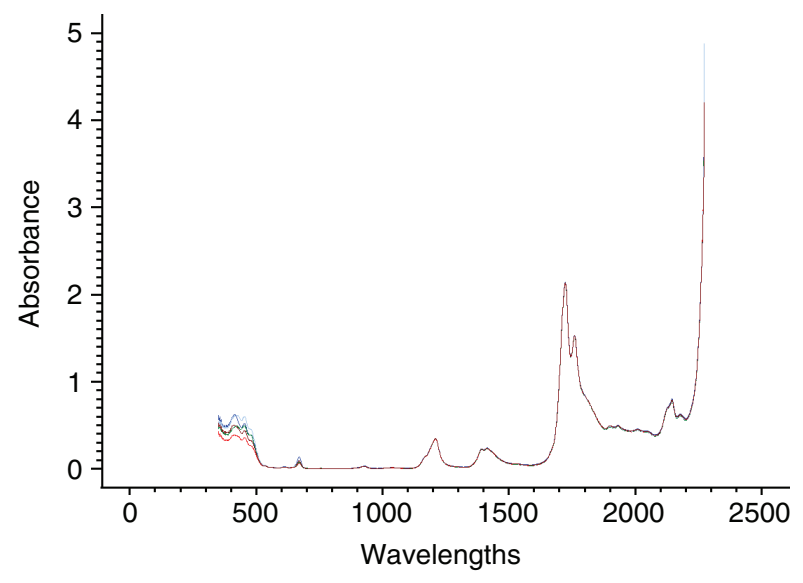

FIgURE 1. Olive oil Vis/NIR absorbance spectrum.

\subsection{Population characterization}

The values from the FAAE, FAEE, and FAME reference analysis corresponding to the calibration and external validation sets are included in Table 1. As can be seen, wide variation ranges of the olive oils studied were integrated into the calibrations of all the parameters analyzed. The FAAEs ranged from $3.0 \mathrm{mg} . \mathrm{kg}^{-1}$ to $520.0 \mathrm{mg} . \mathrm{kg}^{-1}$ in calibration set I and from $13.0 \mathrm{mg} \cdot \mathrm{kg}^{-1}$ to $780.0 \mathrm{mg} \cdot \mathrm{kg}^{-1}$ in calibration set II. The FAAE averages from the calibration sets analyzed were $48.4 \mathrm{mg} . \mathrm{kg}^{-1}$ and $96.3 \mathrm{mg} \cdot \mathrm{kg}^{-1}$, respectively, in calibration sets I and II.

\subsection{Spectral variable analysis and chemometry}

Maximum normalization provided slightly better performance than the mean normalization treatment for the FAAE, FAEE, and FAME calibrations tested. The treatments with first or second Savitzky Golay derivatives did not improve the calibration statistics in the tests (data not shown), which were conducted with the same calibration sets of samples with either of the spectrometers.

The procedure for selecting spectral variables provided a set of wavelengths contributing to the models, including diverse NIR regions. The wavelengths participating in the calibrations are shown in Figure 2, where the regression coefficient graphs from the models for FAAEs, FAMEs and FAEEs obtained from the NIR (1100-2300 nm) spectrometer are depicted. In these graphs, the horizontal line within a certain wavelength indicates zero contribution to the model. The spectral windows corresponding to $1700 \mathrm{~nm}$ and $2100-2200 \mathrm{~nm}$ can be highlighted for their contribution to FAEE and FAAE models.

The calibration from the NIR spectrometer provided the best yields for the quantification of FAAEs, FAEEs and FAMEs. The visible wavelengths tested using the Vis/NIR spectrometer (350$2500) \mathrm{nm}$ did not improve the calibration. Moreover, after the removal of the visible spectrum and selection of spectral variables, the statistics of these last calibrations were lower than those from the exclusively NIR wavelengths using the same method.

\subsection{Fatty acids alkyl esters}

The FAAE calibration statistics from both spectrometers are shown in Table 2. These calibrations come from absorbance spectral data treated with maximum normalization which provided the best fits with both instruments. The NIR model from calibration set I for FAAEs provided R 0.84 and SEC 30.9. The statistic $\mathrm{R}$ was a little lower with Vis/ NIR wavelengths, showing R 0.82 , while SEC was 29.9. Calibration set II gave R 0.94 and SEC 48.2 
TABle 1. Statistics of total Fatty Acid Alkyl Esters (FAAEs), Fatty Acid Ethyl Esters (FAEEs), Fatty Acids Methyl Esters (FAMEs) of the calibration and validation sets.

\begin{tabular}{|c|c|c|c|c|c|c|c|c|}
\hline & \multicolumn{4}{|c|}{$I$} & \multicolumn{4}{|c|}{ II } \\
\hline & $\mathbf{N}$ & Range & $\bar{X}$ & $\sigma$ & $\mathbf{N}$ & Range & $\bar{X}$ & $\sigma$ \\
\hline & \multicolumn{8}{|c|}{ Calibrations } \\
\hline FAAEs & 386 & $3.0-520.0$ & 48.4 & 57.7 & 80 & $13.0-780.0$ & 96.3 & 142.1 \\
\hline FAEEs & 382 & $1.0-214.0$ & 24.7 & 29.9 & 80 & $4.0-609.0$ & 62.3 & 104.6 \\
\hline \multirow[t]{2}{*}{ FAMEs } & & & & & 80 & $5.0-200.0$ & 32.1 & 39.0 \\
\hline & \multicolumn{8}{|c|}{ Validations } \\
\hline $\mathbf{V}_{\mathrm{a}}$ & 97 & $3.0-572.0$ & 50.7 & 78.2 & 40 & $7.0-865.0$ & 127.1 & 190.5 \\
\hline $\mathbf{V}_{\mathrm{e}}$ & 97 & $1.0-361.0$ & 27.7 & 49.8 & 40 & $1.0-652.0$ & 91.1 & 143.0 \\
\hline $\mathbf{V}_{\mathbf{m}}$ & & & & & 40 & $4.0-213.0$ & 36.0 & 47.8 \\
\hline
\end{tabular}

$I$, calibration set I; II, calibration set II; FAAEs, fatty acid alkyl esters (mg.kg $\left.{ }^{-1}\right)$ FAEEs, fatty acid ethyl esters $\left(\mathrm{mg}^{-\mathrm{kg}^{-1}}\right)$; FAMEs, fatty acid methyl esters $\left(\mathrm{mg} . \mathrm{kg}^{-1}\right) ; \mathrm{V}_{\mathrm{a}}$, validation of fatty acid alkyl esters; $\mathrm{V}_{\mathrm{e}}$, validation of fatty acid ethyl esters;

$\mathrm{V}_{\mathrm{m}}$, validation of fatty acid methyl esters.
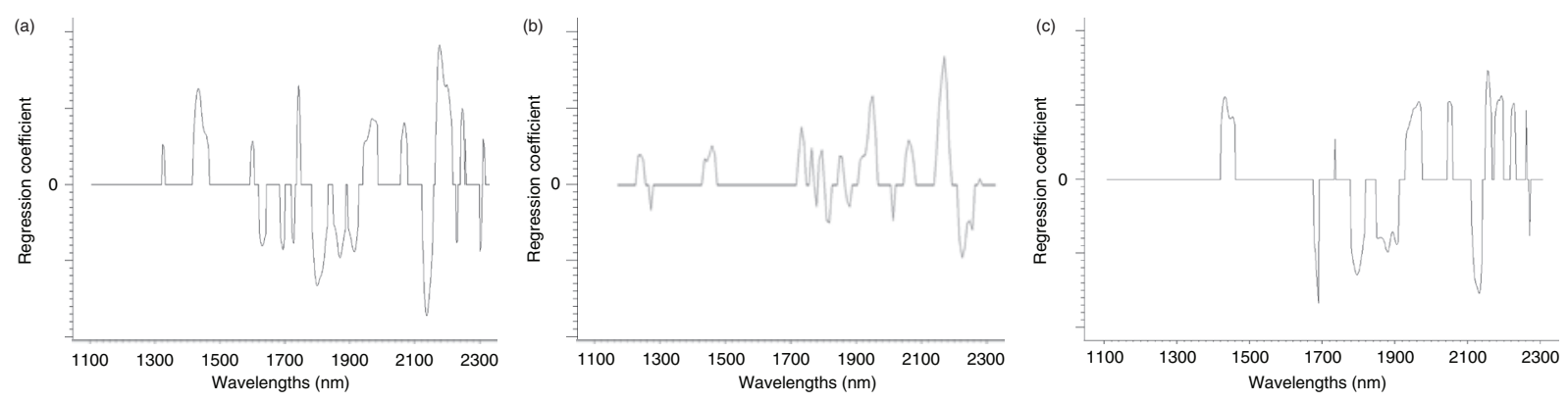

FIGURE 2. Wavelengths contributing to the models of FAAEs (a), FAMEs (b), and FAEEs (c).

TABlE 2. Statistics of the fatty acid alkyl ester, fatty acid ethyl ester, and fatty acid methyl ester models.

\begin{tabular}{|c|c|c|c|c|c|c|c|c|c|}
\hline & & \multicolumn{4}{|c|}{$\begin{array}{c}\text { NIR } \\
(1100-2300 \mathrm{~nm})^{1}\end{array}$} & \multicolumn{4}{|c|}{$\begin{array}{c}\text { Vis/NIR } \\
(350-2500 \mathrm{~nm})^{2}\end{array}$} \\
\hline & & \multicolumn{2}{|c|}{ Calibration } & \multicolumn{2}{|c|}{ Validation } & \multicolumn{2}{|c|}{ Calibration } & \multicolumn{2}{|c|}{ Validation } \\
\hline & & $\mathrm{R}^{\mathrm{a}}$ & $\mathrm{SEC}^{\mathrm{b}}$ & SEP $^{\mathrm{c}}$ & $r$ & $\mathrm{R}^{\mathrm{a}}$ & SEC $^{\mathrm{b}}$ & SEP $^{c}$ & $r$ \\
\hline \multirow[t]{2}{*}{ FAAEs } & $I$ & 0.84 & 30.9 & 33.6 & 0.91 & 0.82 & 29.9 & 43.2 & 0.84 \\
\hline & $I I$ & 0.94 & 48.2 & 54.5 & 0.93 & 0.92 & 55.0 & 90.9 & 0.89 \\
\hline \multirow[t]{2}{*}{ FAEES } & $I$ & 0.81 & 17.5 & 25.6 & 0.89 & 0.79 & 19.5 & 29.3 & 0.84 \\
\hline & $I I$ & 0.94 & 28.5 & 67.2 & 0.88 & 0.93 & 39.8 & 74.5 & 0.84 \\
\hline$F A M E s$ & $I I$ & 0.95 & 12.6 & 18.7 & 0.92 & 0.92 & 15.2 & 23.4 & 0.91 \\
\hline
\end{tabular}

${ }^{1}$ Initial wavelengths used from the NIR optical configuration

${ }^{2}$ Initial wavelengths used from the Vis/NIR optical configuration

${ }^{\text {a }}$ Model coefficient of calibration; ${ }^{\mathrm{b}}$ Standard error of calibration;

${ }^{\mathrm{c}}$ Standard error of performance; ${ }^{d}$ Residual predictive deviation.

FAAES, fatty acid alkyl esters; FAEES, fatty acid ethyl esters;

FAMES, fatty acid methyl esters.

using only NIR spectra, and R 0.92 and SEC 55.0 with Vis/NIR.

The predictions of the external validation exercises, carried out by using the best models to measure FAAEs on sets of 97 and 40 samples initially reserved for this purpose are shown in Figure 3. The
FAAE model performance was satisfactory, according to the $r 0.91$ and 0.93 , respectively, for sample sets I and II. The same statistics $r$ from Vis/NIR wavelengths were somewhat worse, with values of 0.84 and 0.89 , and the SEP values were worse with this optical configuration (Table 2). 


\subsection{Fatty acids ethyl esters}

The FAEE calibration statistics are included in Table 2. The model from the NIR instrument gave $R$ 0.81 and SEC 17.5 with calibration set I, and R 0.94 and SEC 28.5 with calibration set II. In addition, the Vis/NIR optical configuration provided R 0.79 and SEC 19.5 with calibration set I, and R 0.93 and SEC 39.8 with calibration set II.

A sample with a FAEE value of $652 \mathrm{mg} \cdot \mathrm{kg}^{-1}$ was included in validation set II, the only one higher than $400 \mathrm{mg} \cdot \mathrm{kg}^{-1}$. Taking into account the EU regulation the main interest is measuring the FAEE contents higher than $35 \mathrm{mg} \cdot \mathrm{kg}^{-1}$ within a usual range. Thus, the usual range of the FAEE calibration has been considered to be up to $400 \mathrm{mg} \cdot \mathrm{kg}^{-1}$. Therefore, the referred sample was removed from the validation set.

The external validation exercise of FAEEs using the NIR spectrometer provided SEP values of 25.6 and 67.2 and $r 0.89$ and 0.88 , respectively for validation sets I and II. The same statistics were worse with the Vis/NIR instrument, showing SEP values of 29.3 and 74.5, and $r 0.84$ and 0.84 , respectively, for validation sets I and II. These predictions using the Vis/NIR instrument, for sample groups I and II are shown in Figure 4, and their statistics are gathered in Table 2.
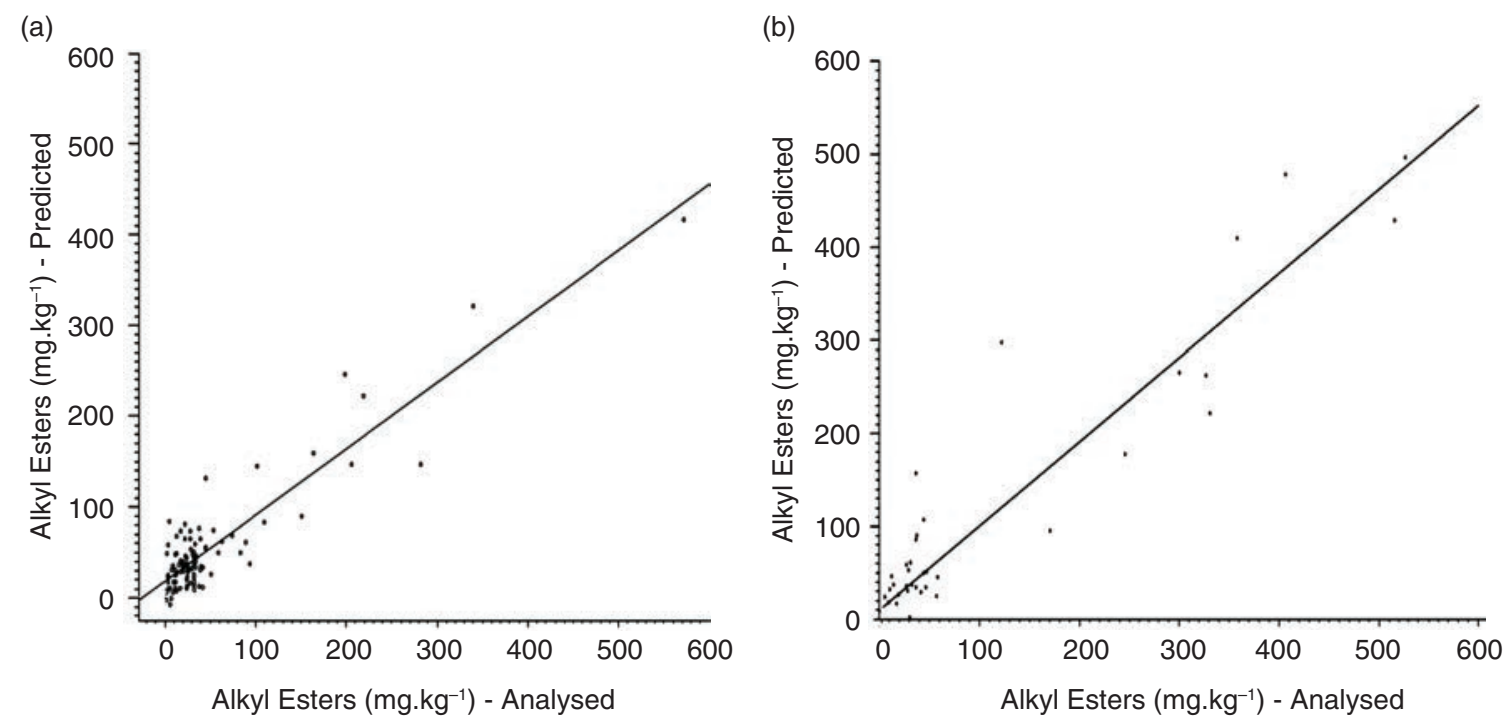

FIGURE 3. External validations of fatty acid alkyl ester models. $a$, calibration set $I ; b$, calibration set $I I$.

(a)

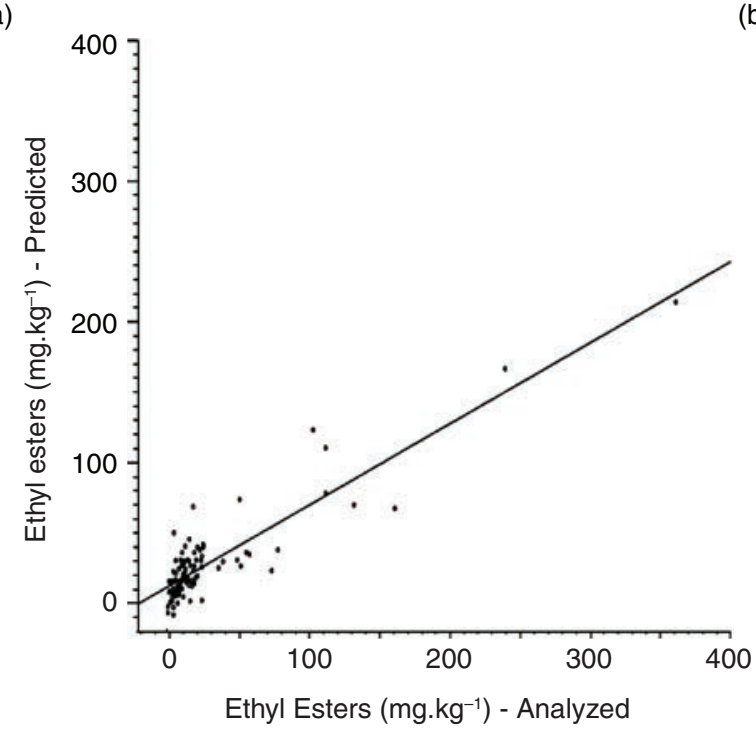

(b)

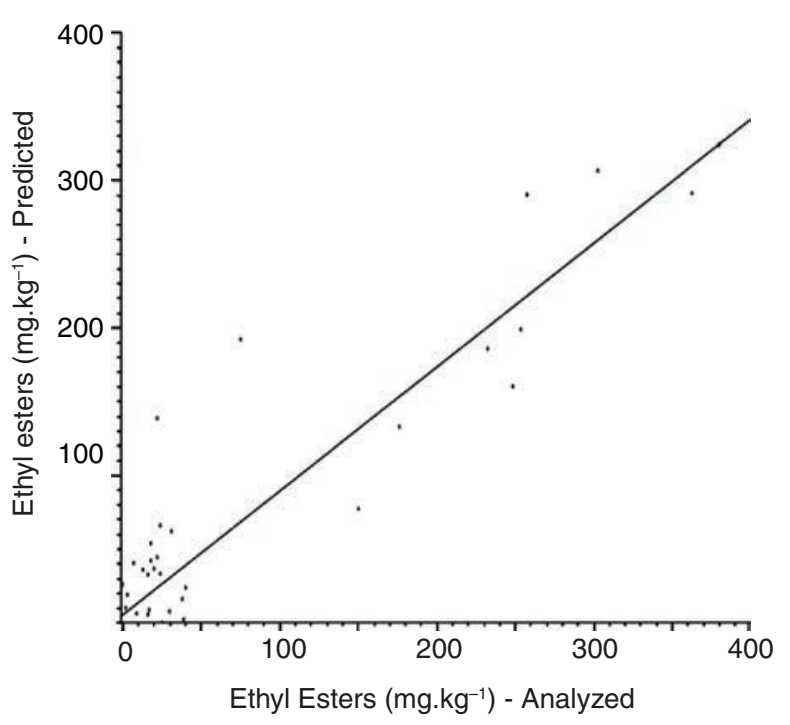

FIgURE 4. External validations of fatty acid ethyl ester models. $a$, calibration set $I ; b$, calibration set $I I$. 


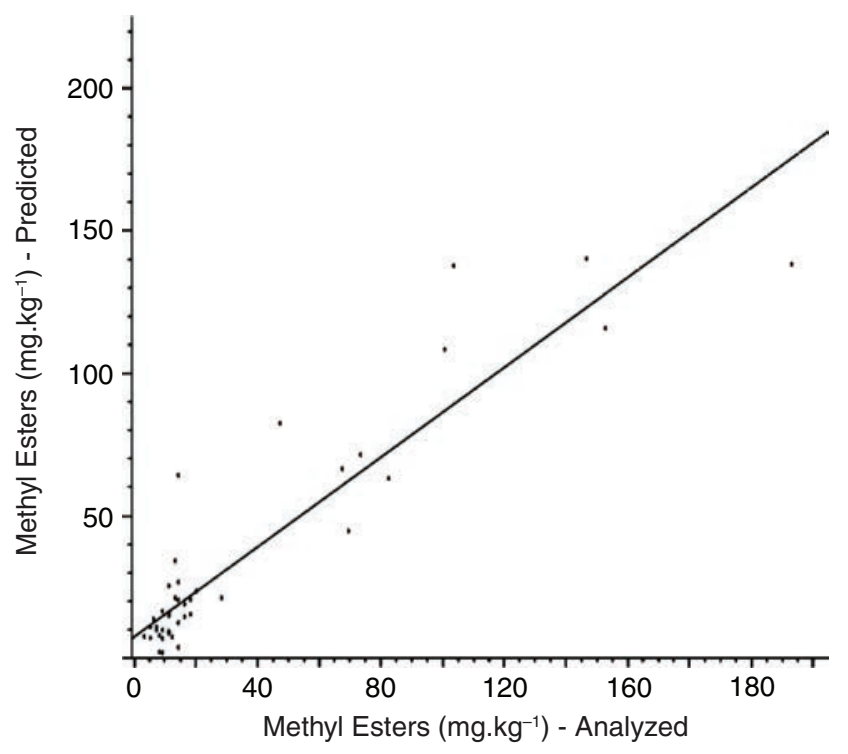

FIGURE 5. External validations of fatty acids methyl ester models. Calibration set II.

\subsection{Fatty acids methyl esters}

Calibration for FAMEs was performed only with the sample group II. The optical configuration using NIR wavelengths from the spectrum comprised between 1100 to $2300 \mathrm{~nm}$ provided the best outcomes, the same as with FAAEs and FAEEs. The model from the NIR instrument with sample set II gave R 0.95 and SEC 12.6. These statistics are gathered in Table 2.

Prediction exercises were carried out, as external validations, by using the FAME models to measure the 40 olive oil samples initially reserved and the same one was used for predicting FAAEs and FAMEs, whose statistics are shown in Table 2. This prediction using the NIR spectrometer, depicted in Figure 5, provided a SEP value of 18.7 and $r$ of 0.92 . The Vis/NIR instrument provided lower statistics, with values for SEP of 23.4 and $r$ of 0.91 .

\subsection{Classification exercises}

The models from the NIR configuration were used for classifying the samples of the external validations as higher or lower than the arbitrary threshold of $75 \mathrm{mg} \cdot \mathrm{kg}^{-1}$. The samples composing validation set I were classified regarding this threshold using the FAAE model I. This model was successful at classifying $94.8 \%$ of the total samples. At the same time, the model correctly classified $78.65 \%$ of the samples from validation set I, whose FAAEs were higher than $75 \mathrm{mg} \cdot \mathrm{kg}^{-1}$. Model II of FAAEs provided $90.5 \%$ success in the same classification on the total samples of validation set II.

Similarly, the prediction with FAEE model I provided correct classification of $88.7 \%$ of validation set
I regarding the threshold of $35 \mathrm{mg} \cdot \mathrm{kg}^{-1}$, regulated by the EU (European Commission Regulation, 2016), and was successful in the classification of $75.0 \%$ of the 16 samples whose FAEE values were higher than this threshold. Model II of FAEEs provided 70.0\% success in this classification on the total samples of validation set II.

The EU regulation on FAAEs does not establish any threshold for FAMEs as such, although a similar classification exercise with FAME model II provided a correct classification of $95.2 \%$ of validation set II, considering the same threshold of $35 \mathrm{mg} \cdot \mathrm{kg}^{-1}$ as for FAEEs.

\section{DISCUSSION}

The major near-infrared absorption bands of the olive oils analyzed in the current study agreed with the literature. The wide variation range of the FAAEs shown in these olive oils must be highlighted as it brings significant value to the database established.

The null contribution of the visible spectrum to the predictive models of FAEEs and FAMEs was confirmed, which was expected since no pigmented compounds related to the content of FAAEs had been identified a priori. Besides, the best results for FAAEs, FAEEs and FAMEs were provided by the spectrometer using exclusively NIR wavelengths (1100-2300 nm) and transflectance configuration.

Time domain reflectometry (Berardinelli et al., 2013) and mid infrared spectroscopy (Valli et al., 2013), the only techniques which are rapid and without sample preparation for analyzing FAAEs reported previously, may be suitable according to the results reported, while the cost of the required 
equipment may be analogous to the case of the NIR technique. However, the versatility of NIR spectroscopy may make this analysis of FAAEs possible for olive oil and olive mill laboratories, when they already have instrumentation to be used for other previous applications. Thus, particularly, but not only in those cases, NIR spectroscopy may be an advantageous method for analyzing FAAEs in olive oils. However, if routine analysis is intended, the technique requires some improvement. Also, as is normal in NIRS, a procedure for testing the model's operation periodically is necessary.

\section{CONCLUSIONS}

Considering the results above for quantitative predictions and classifications together, PLS models based on NIR spectroscopy can provide a useful tool for early detection of virgin olive oil's FAAEs and FAEEs.

The results of the present research indicate that NIR predictive models of FAAEs and FAEEs can provide an alternative method for the detection of these parameters in virgin olive oil. This technique is characterized as rapid, non-destructive, environmentally friendly and potentially multi-parametric. This also implies the early detection of fermentation defects in virgin olive oil, which is also useful for non-destructively monitoring its quality.

\section{ACKNOWLEDGMENTS}

The author is sincerely grateful to The AINIA Technology Center (Paterna, Spain) for providing part of the olive oil samples and data from the FAAE, FAEE and FAME reference analysis used in this work.

\section{REFERENCES}

Alba J. 2013. Forecasts of the 2013 campaign. II Foss Meeting with the olive sector. Instituto de la Grasa, CSIC, Sevilla. September, 19

Armenta S, Garrigues S, De la Guardia M. 2007. Determination of edible oil parameters by near infrared spectrometry. Anal. Chim. Acta 596, 330-337. http://dx.doi.org/10.1016/j. aca.2007.06.028

Bendini A, Cerretani L, Di Virgilio F, Belloni P, Lercker G, Gallina-Toschi T. 2007. In-process monitoring in industrial olive mill by means of FT-NIR. Europ. J. Lipid Sci. Technol. 109, 498-504. http://dx.doi.org/10.1002/ ejlt. 200700001

Berardinelli A, Ragni L, Bendini A, Valli E, Conte L, Guarnieri A, Toschi TG. 2013. Rapid Screening of Fatty Acid Alkyl Esters in Olive Oils by Time Domain Reflectometry. J. Agric. Food Chem. 61, 10919-10924. http://dx.doi. org/10.1021/jf402872m
Boggia R, Borgogni C, Hysenaj V, Leardi R, Zunin P. 2014. Direct GC-(EI) MS determination of fatty acid alkyl esters in olive oils. Talanta 119, 60-67. http://dx.doi.org/10.1016/j. talanta.2013.10.055

Cayuela JA, Moreda W, García JM. 2013. Rapid Determination of Olive Oil Oxidative Stability and Its Major Quality Parameters Using Vis/NIR Transmittance Spectroscopy. J. Agric. Food Chem. 61, 8056-8062. http://dx.doi.org/10.1021/ jf4021575

Cayuela JA, Gómez R, Moreda W, Pérez-Camino, MC. 2015. Sensory defects of virgin olive oil from a microbiological perspective. Trends in Food Sci. Technol. 43, 227-235. http://dx.doi.org/10.1016/j.tifs.2015.02.007

Conte LS, Mariani C. 2013. A critical evaluation of some methods used to assess purity of olive oils. Workshop on authentication of olive oil. Madrid, June 2013, 10-11.

Costa AF, Coelho MJ, Gambarra FF, Bezerra SR, Harrop RK, Ugulino MC. 2008. NIR spectrometric determination of quality parameters in vegetable oils using PLS and variable selection. Food Res. Int. 41, 341-348. http://dx.doi. org/10.1016/j.foodres.2007.12.013

European Commission Regulation. 1991. Regulation Nr. 2568/91 of the Comission on the characteristics of olive oils and olive pomace oils and their analytical methods.

European Commission Regulation. 2016. Commission Delegated Regulation 2016/2095 of 26 September 2016 amending Regulation (EEC) No 2568/91

García-González DL, Baeten V, Fernández JA, Tena N. 2013. Infrared, raman, and fluorescence spectroscopies: Methodologies and applications. In Aparicio R and Harwood J (Eds.) Handbook of Olive Oil: Analysis and Properties. $2^{\text {nd }}$ ed. Springer, New York, 363. http://dx.doi. org/10.1007/978-1-4614-7777-8 10

Gómez-Coca RB, Moreda W, Pérez-Camino M. 2012. Fatty acid alkyl esters presence in olive oil vs. organoleptic assessment. Food Chemistry 135, 1205-1209. http://dx.doi. org/10.1016/j.foodchem.2012.05.053

Gómez-Coca RB, Fernandes GB, Pérez-Camino MC, Moreda W. 2016. Fatty acid ethyl esters (FAEE) in extra virgin olive oil: A case study of a quality parameter. $L W T$ - Food Sci. Technol. 66, 378-383. http://dx.doi.org/10.1016/j. lwt.2015.10.063

Hourant P, Baeten V, Morales MT, Meurens M, Aparicio R. 2000. Oil and fat classification by selected bands of nearinfrared spectroscopy. Appl. Spectrosc. 54, 1168-1174.

Mailer RJ. 2004. Rapid evaluation of olive oil quality by NIR reflectance spectroscopy. J. Am. Oil Chem. Soc 81, 823-827.

Moyano MJ, Meléndez AJ, Alba J, Heredia FJ. 2008. A comprehensive study on the colour of virgin olive oils and its relationship with their chlorophylls and carotenoids indexes (I): CIEXYZ non-uniform colour space. Food Res. Int. 41, 505-512. http://dx.doi.org/10.1016/j.foodres.2008.03.007

Pérez-Camino MC, Moreda W, Mateos R, Cert A. 2002. Determination of esters of fatty acids with low molecular weight alcohols in olive oils. J. Agric. Food Chem. 50, 4721-4725. http://dx.doi.org/10.1021/jf025542

Procida G, Giomo A. Cichelli A. Conte LS. 2005. Study of volatile compounds of defective virgin olive oils and sensory evaluation: a chemometric approach. J. Sci. Food Agric. 85, 2175-2183. http://dx.doi.org/10.1002/jsfa.2122

Sato T, Kawano S, Iwamoto M. 1991. Near-infrared spectral patterns of fatty acid analysis from fats and oils. J. Am. Oil Chem. Soc. 68, 827-833. http://dx.doi.org/10.1007/ BF02660596

Valli E Bendini A, Maggio R, Cerretani L, Toschi TG, Casiraghi E, Lercker G. 2013. Detection of low-quality extra virgin olive oils by fatty acid alkyl esters evaluation: a preliminary and fast mid-infrared spectroscopy discrimination by a chemometric approach. Int. J. Food Sci. Technol. 48, 548-555. 